\title{
ICOS and B7 Costimulatory Molecule Expression Identifies Activated Cellular Subsets in Rheumatoid Arthritis
}

\author{
Jeffrey H. Ruth, ${ }^{1,2 *}$ James B. Rottman, ${ }^{4}$ Gillian A. Kingsbury, ${ }^{5}$ Anthony J. Coyle, ${ }^{4}$ \\ G. Kenneth Haines III, ${ }^{3}$ Richard M. Pope ${ }^{2}$ and Alisa E. Koch ${ }^{1,2,6}$ \\ ${ }^{1}$ Department of Internal Medicine, University of Michigan Medical School, Ann Arbor, Michigan 48109 \\ ${ }^{2}$ Department of Internal Medicine, Northwestern University Feinberg School of Medicine, \\ Chicago, Illinois 60611 \\ ${ }^{3}$ Department of Pathology, Northwestern University Feinberg School of Medicine, \\ Chicago, Illinois 60611 \\ ${ }^{4}$ Inflammation and ${ }^{5}$ Experimental Medicine Divisions, Millenium Pharmaceuticals Inc., Cambridge, Massachusetts 02142 \\ ${ }^{6}$ Veteran's Administration, Ann Arbor, Michigan 48109
}

Received 21 March 2006; Accepted 27 October 2006

To better define important cell subsets expressing activation markers in rheumatoid arthritis (RA), we compared selective lymphocyte and monocyte B7H1, B7H2, B7RP.1, B7RP.2, and inducible costimulatory molecule (ICOS) expression from normal peripheral blood (NL PB), RA PB, and RA synovial fluid (SF) by multicolor flow cytometry and immunohistochemistry. RA SF memory lymphocytes expressed B7RP.1 and B7RP.2, suggesting that T-cells may function as antigen presenting cells (APCs) in RA joints. We found similar results for ICOS expression. RA SF CD14+ monocytes also expressed B7RP.1 (an ICOS ligand) and the homologous ligand B7RP.2, identifying monocytes as potential mediators of antigen processing and lymphocyte activation in RA. Furthermore, we found an increased population of RA SF CD14+ monocytes expressing $\mathrm{B} 7 \mathrm{H} 1$ and $\mathrm{B} 7 \mathrm{H} 2$. [The FACS analysis was sup- ported by immunohistochemistry, showing intense lymphocyte and APC (macrophages with dendritic morphology) ICOS staining in RA synovial tissue (ST). Overall, these results define elevated populations of memory T-lymphocytes expressing proinflammatory B7 molecules in RA SF that either stimulate T cells through ICOS (via ICOS ligands B7RP.1 and B7RP.2), or down-regulate RA ST T-lymphocytes through $\mathrm{B} 7 \mathrm{H} 1$ and $\mathrm{B} 7 \mathrm{H} 2$.] Therefore, in the same joint, there may exist positive and negative influences on the inflammatory response, and perhaps, the negative signals dominate as joint inflammation resolves. (C) 2007 International Society for Analytical Cytology

Key terms: rheumatoid arthritis; B7; ICOS; inflammation; antigen presentation
The inducible costimulatory molecule (ICOS) is a T-cell associated receptor involved in cell activation that is conservatively expressed on memory T-cell subsets (1). ICOS is a $60 \mathrm{kDa}$, disulfide-linked, glycosylated homodimer (1) expressed on T-lymphocytes in lymphoid organs, such as spleen, lymph node, and Peyers patches in both humans and mice (1-5). ICOS expressing T cells are also found in germinal centers that are enhanced after immune priming $(1,5)$. ICOS performs several functions in immune activation including binding $\mathrm{B} 7$ accessory molecules on antigen presenting cells (APCs). This binding results in activation of responding lymphocytes $(1,3)$. Because they activate T-cells, ICOS and T-lymphocyte associated molecules, CTLA4 and CD28, have been designated as potential therapeutic targets to treat inflammatory diseases. Akin to ICOS, CD28 and CTLA4 are quite unique in that these molecules better define immune function. For example, B7 ligands found on dendritic cells (and on B-lymphocytes and monocytes) bind to both T-cell associated CD28 (activating) and CTL4 (inhibitory) cell receptors. After engagement of antigen and accessory molecules by the T-cell receptor (TCR), B7 ligands will direct T-cell responses (1). Therefore, cell-mediated immunity continues unimpeded or is attenuated depending upon which TCR is bound.

\footnotetext{
${ }^{*}$ Correspondence to: Jeffrey H. Ruth; Research Assistant Professor of Internal Medicine, University of Michigan Medical School, Division of Rheumatology, 109 Zina Pitcher Place. 4380 BSRB, Box 2200, Ann Arbor, MI 48109-2200. E-mail: jhruth@umich.edu

Published online 23 February 2007 in Wiley InterScience (www interscience.wiley.com).

DOI: $10.1002 /$ cyto.a. 20383
} 
Interestingly, expression of ICOS on T lymphocytes depends upon TCR and CD28 signaling mechanisms. Activation of $\mathrm{T}$ cells without $\mathrm{CD} 28$ engagement results in diminished levels of T-cell ICOS expression $(1,6)$. Although complex, this elegant system ensures that immune responses are turned on or off appropriately. This process has been demonstrated in vivo in a murine model of experimental allergic encephalomyelitis (EAE) in which it was shown that ICOS protein and mRNA levels were upregulated on infiltrating $\mathrm{CD} 3+$ T-cells directly before disease onset (7). ICOS blockade during the efferent immune response (9-20 days after immunization) abrogated EAE development (7). This finding was supported in murine collagen induced arthritis (CIA) in which blocking $\mathrm{B} 7$ and ICOS interactions significantly ameliorated joint inflammation (8). It was also reported that ICOS gene deficient mice bred on the CIA susceptible DBA-1 background were completely resistant to CIA development, joint inflammation, and proinflammatory cytokine expression (9).

The data presented in this study extend and clarify the expression of ICOS and B7 costimulatory molecules in rheumatoid arthritis (RA). We define the expression of ICOS, B7H1, B7H2, B7RP.1, and B7RP.2 on CD14+ monocytes, and on naive (CD45RA+) and memory (CD45RO+) lymphocytes from normal (NL) peripheral blood (PB), RA $\mathrm{PB}$, and RA synovial fluid (SF) by flow cytometry. We further show by immunohistochemistry that the ligands for ICOS, namely B7RP.1 and its homologous ligand B7RP.2, are prominently expressed on RA synovial tissue (ST) macrophages, whereas RA ST lymphocytes express ICOS. This data indicates that lymphocyte ICOS expression, and the macrophage associated ligands B7RP.1 and B7RP.2 are expressed in RA, and may be responsible, at least in part, for the progressive inflammatory responses observed in the RA joint.

\section{MATERIALS AND METHODS Patient Samples}

SF samples were obtained during arthrocentesis from patients with RA, and PB was collected in heparinized tubes from patients with RA or from healthy NL volunteers. STs from RA patients were obtained from patients undergoing total joint replacement who met the American College of Rheumatology criteria for RA.

\section{Flow Cytometry}

SF cells were collected by passing RA SF through a $40 \mu \mathrm{m}$ nylon mesh filter. Filtered SF was centrifuged, leaving a cell pellet. RA SF cells were washed $3 \times$ in FACS buffer [PBS/1\% fetal bovine serum (FBS)] and resuspended at a concentration of $1 \times 10^{7}$ cells $/ \mathrm{ml}$ in blocking buffer (1\% BSA/0.1\% NaN3/30\% goat serum in PBS) for 15 min at $4^{\circ} \mathrm{C}$. SF cells $\left(1 \times 10^{6}\right.$ per tube $)$ or $100 \mathrm{ml}$ of whole blood were incubated with primary antibodies directed against ICOS, B7H1, B7H2, B7RP.1, and B7RP.2 or appropriate IgG isotype controls (Sigma, St. Louis, MO) at $5 \mathrm{mg} / \mathrm{ml}$ in blocking buffer for $30 \mathrm{~min}$ at $4^{\circ} \mathrm{C}$. Cells were washed with
FACS buffer, then incubated with goat anti-mouse IgG Rphycoerythrin (PE; Jackson Immunoresearch Laboratory, West Grove, PA) diluted 1:100 in blocking buffer for 30 min at $4^{\circ} \mathrm{C}$. Cells were washed and incubated with $20 \mu \mathrm{l}$ mouse serum for $10 \mathrm{~min}$ at room temperature (RT). Cychrome-conjugated CD3 (detects T cells) mAbs (PharMingen, San Diego, CA) were added for $30 \mathrm{~min}$ at $4^{\circ} \mathrm{C}$.

We evaluated ICOS or B7 costimulatory receptor family expression on naive or memory leukocytes by incubating cells with either FITC-labeled mouse anti-human CD45RA (PharMingen, San Diego, CA), which detects naive leukocytes, or mouse anti-human CD45RO (PharMingen, San Diego, CA), which detects memory leukocytes. SF cells were washed $2 \times$ in FACS buffer and fixed in $500 \mu \mathrm{l}$ of fresh $1 \%$ formaldehyde in PBS. Whole blood RBCs were lysed with Becton-Dickinson Lysing Reagent (BectonDickinson, Mountain View, CA) before fixation. ICOS and B7 expression on lymphocytes and monocytes was determined by first gating on cells using side scatter properties. Receptor expression on cells was determined by a second histogram of the gated $\mathrm{CD} 3+$ lymphocytes (FITC) or CD14+ monocytes (FITC) against ICOS or B7 molecule expression (PE) fluorescence. For some studies, chemokine receptor expression on lymphocyte subsets was evaluated by incubating cells with anti-CD4-ECD or anti-CD8ECD labeled antibodies (Beckman-Coulter, Miami, FL), added along with FITC (anti-CD45RA or anti-CD45RO) and cychrome (anti-CD3, PharMingen, San Diego, CA) labeled antibodies, using additional histograms to evaluate memory or naive $\mathrm{CD} 3+/ \mathrm{CD} 4+$ and $\mathrm{CD} 3+/ \mathrm{CD} 8+$ positive lymphocytes. Cells were analyzed using a Coulter Epics XL flow cytometer (Coulter, Hialeah, FL) and the percentages of positive cells determined. The numbers of cell analysis counts were routinely between 75,000 and 200,000 events per tube, depending on the experiment, with $\sim 1 \times 10^{6}$ cells per tube for all experiments. Percentages of cells expressing ICOS or a particular B7 costimulatory molecule were calculated after defining a background value for the isotype matched control antibody.

\section{Immunohistochemistry}

Frozen RA ST sections $(7 \mu \mathrm{m})$ were cut and immunoperoxidase stained with an avidin-biotin technique (Vector Laboratories, Burlingame, CA) with all subsequent incubations being performed at $37^{\circ} \mathrm{C}$ in a humidified chamber. Slides were fixed in cold acetone for $20 \mathrm{~min}$, then treated with 3\% peroxidase in $0.1 \mathrm{M}$ Tris for $5 \mathrm{~min}$ to block endogenous peroxidase activity. Tissues were blocked with 3\% horse serum (in PBS) for $1 \mathrm{~h}$, then incubated with mouse $10 \mu \mathrm{g} / \mathrm{ml}$ anti-human antibody (Millennium Pharmaceuticals, Cambridge, MA), or purified nonspecific mouse antibody negative control (Coulter, Miami, FL) for an additional hour. Antibodies against ICOS, B7H1, B7H2, B7RP.1, and B7RP.2 (Millennium Pharmaceuticals, Cambridge, MA) were made as previously described (10). Tissue was washed twice in PBS, and a 1:200 dilution (in PBS) of antimouse biotinylated antibody (Vector Laboratories, Burlingame, MA) was added to the tissue sections and incubated 
for an additional $20 \mathrm{~min}$. After a final washing $(2 \times$ in PBS), slides were developed with a diaminobenzidine tetrahydrochloride substrate (Vector Laboratories) for 2 min at RT, rinsed in tap water, counter-stained with Harris' Hematoxylin, and dipped in saturated lithium carbonate solution for bluing.

[Serial tissue sections were examined by a blinded pathologist to determine the percentage of each cell type expressing B7 molecules in NL and RA ST. Various ST cell types were identified including macrophages, lymphocytes, fibroblasts, endothelial cells, and APCs with dendritic morphology (referred to as dendritic-like cells) by immunohistochemical staining reaction and/or morphological features. Human macrophages were identified morphologically and with anti-LeuM5 (Becton Dickinson, San Jose, CA) and were CD68+ (CD68 stain is clone EBM-11, Dako, IgG1, Carpinteria, CA) in serial sections. Endothelium was verified using anti-von Willebrand's factor (Dako, Carpinteria, CA). Dendritic-like cells were identified with a dendritic cell marker (OX-62 IgG, PharMingen, San Diego, CA) as previously described (11). Immunostaining was graded by a frequency of staining scale (0-100\%), where $0 \%$ indicated no staining and $100 \%$ showed that all the cells were immunoreactive for each of the ST components.]

\section{Statistics}

PB and SF samples were analyzed by the Student's independent $t$ test. Comparisons of values where $P<0.05$ were considered to indicate statistical significance. Error bars on graphs represent the standard error of the mean.

\section{RESULTS}

Flow Cytometry Analysis of CD3 + Lymphocytes in NL PB, RA PB, and RA SF

Two color FACS analysis of CD3 + lymphocyte populations obtained from $\mathrm{NL} \mathrm{PB}, \mathrm{RA} \mathrm{PB}$, and $\mathrm{RA} \mathrm{SF}$ for ICOS and B7 molecule expression is shown in Figure 1. FACS analysis revealed a significant CD3 + lymphocyte population in RA SF expressing B7RP.1 and B7RP.2 compared to lymphocyte populations in NL or RA PB (Fig. 1).

Four-Color Flow Cytometry Analysis of Naive CD45RA+/CD3+/CD4+ and CD45RA+/CD3+/CD8+ Lymphocyte Subsets in NL PB, RA PB, and RA SF

We preformed FACS analysis of ICOS, B7RP.1, B7RP.2, $\mathrm{B} 7 \mathrm{H} 1$, and $\mathrm{B} 7 \mathrm{H} 2$ expression on naive $\mathrm{CD} 45 \mathrm{RA}+/ \mathrm{CD} 3+/$ $\mathrm{CD} 4+$ and CD45RA $+/ \mathrm{CD} 3+/ \mathrm{CD} 8+$ lymphocytes from NL PB, RA PB, and RASF. This is highlighted in Figure 2, where it is clear that naive CD45RA+/CD3+/CD4+ lymphocytes did not significantly express either ICOS or B7 molecules in any of the patient fluids examined (Fig. 2A, upper panel), with groups showing the percentage of expression under 1\%. Figure 2B (lower panel) shows the FACS analysis for CD45RA +/CD3+/CD8+ lymphocytes in which expression of ICOS and $\mathrm{B} 7$ costimulatory mole-

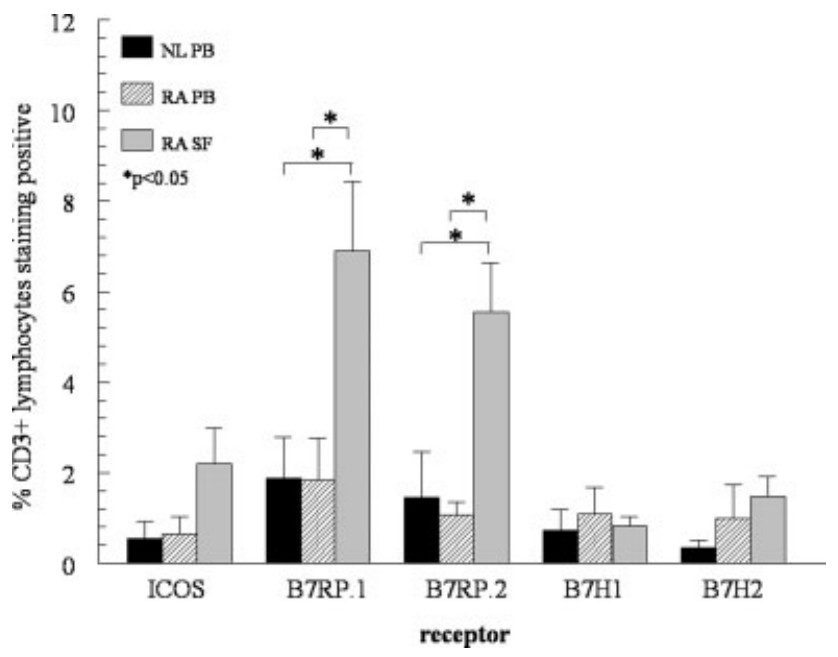

FIG. 1. Percentages of CD3 + lymphocytes from PB (ICOS $n=4$; B7RP. $1 n=4 ; \mathrm{B} 7 \mathrm{RP} .2 n=4 ; \mathrm{B} 7 \mathrm{H} 1 n=4 ; \mathrm{B} 7 \mathrm{H} 2 n=4)$, RA PB (ICOS $n=$ 5; B7RP.1 $n=4$; B7RP. $n=4$; B7H1 $n=4$; B7H2 $n=4$ ), and RA SF (ICOS $n=8$; B7RP.1 $n=7$; B7RP $2 n=7 ; \mathrm{B} 7 \mathrm{H} 1 n=7 ; \mathrm{B} 7 \mathrm{H} 2 n=6$ ) Note the increased populations of B7RP.1 and B7RP.2 expressing CD3+ lymphocytes in RA SF compared to NL and RA PB ( $n$, number of different patients).

cules were all relatively low for all groups, lacking statistical significance for ICOS and B7 molecules examined between the NL PB, RA PB, and RA SF groups. The lack of ICOS and $\mathrm{B} 7$ molecule expression on $\mathrm{CD} 3+/ \mathrm{CD} 4+/$ $\mathrm{CD} 45 \mathrm{RA}+$ and CD3+/CD8+/CD45RA+ lymphocytes is not surprising since we typically do not find large populations of naive lymphocytes in RA SF on whom inflammatory markers such as chemokine receptors are usually expressed (10).

[It should be noted that the percentages of naive T-cells, including CD3/CD4 and CD3/CD8 are low in the RA SF, but higher in the RA and NL PB. Specifically, T-cells carrying the CD45RA+ or CD45RO+ phenotypes are $\sim 30-40 \%$ in the NL and RA PB, however, only $10 \%$ of naive T-cells compared to $40 \%$ of activated T-cells are in the RA SF (10). This is presumably a result of the inflammatory environment of the RA joint activating local T-cell populations.]

\section{Four-Color Flow Cytometry Analysis of Memory $\mathrm{CD} 45 \mathrm{RO}+/ \mathrm{CD} 3+/ \mathrm{CD} 4+$ and $\mathrm{CD} 45 \mathrm{RO}+/ \mathrm{CD} 3+/$ CD8+ Lymphocyte Subsets in NL PB, RA PB, and RA SF}

Figure 3A (upper panel) shows the overall results of memory lymphocyte CD45RO+/CD3+/CD4+ ICOS, B7RP.1, B7RP.2, B7H1, and B7H2 expression from NL PB, RA PB, and RA SF. As shown, the percentages of B7RP.1 and B7RP.2 expressing lymphocytes were significantly elevated in RA SF compared to NL PB and RA PB; whereas no significant differences were found in the groups expressing $\mathrm{B} 7 \mathrm{H} 1$ or $\mathrm{B} 7 \mathrm{H} 2$.

Figure 3B shows the population of memory $\mathrm{CD} 45 \mathrm{RO}+/$ $\mathrm{CD} 3+/ \mathrm{CD} 8+$ ICOS, B7RP.1, B7RP.2, B7H1, and B7H2 

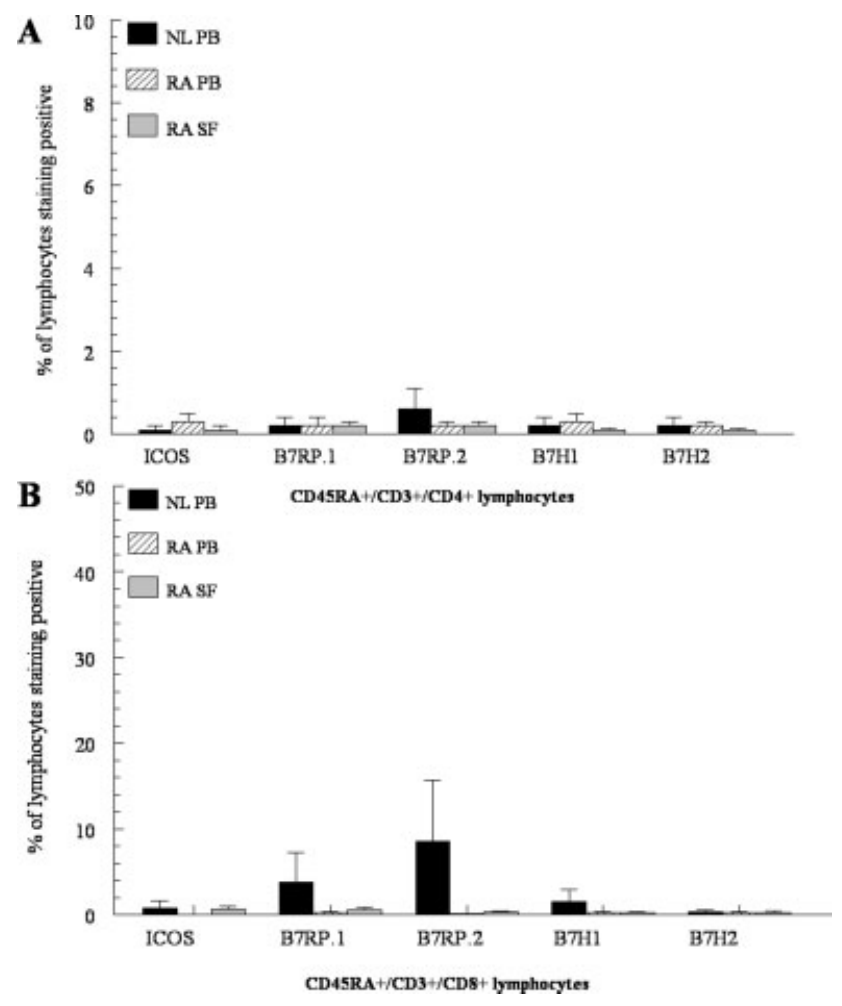

FIG. 2. Comparisons of the number of naïve CD $45 \mathrm{RA}+/ \mathrm{CD} 3+/ \mathrm{CD} 4+$ lymphocytes from NL PB (ICOS $n=4$; B7RP. $1 n=4$; B7RP. $2 n=4$; B 7H1 $n=4 ; \mathrm{B} 7 \mathrm{H} 2 n=4)$, RA PB (ICOS $n=5$; B7RP. $1 n=4$; B 7 RP. $2 n=4$; B7H1 $n=4$; B7H2 $n=4$ ), and RA SF (ICOS $n=8$; B7RP. $1 n=7$; B7RP.2 $n=7$; $37 \mathrm{H} 1 n=7$; B7H2 $n=7$; upper panel) and CD45RA+/CD3+/ CD8+ lymphocytes from NL PB (ICOS $n=4$; B7RP. $1 n=4$; B7RP. $2 n=$ 4; B7H1 $n=4$; B7H2 $n=4$ ), RA PB (ICOS $n=5$; B7RP. $n=4$; B7RP.2 $n=4 ; \mathrm{B} 7 \mathrm{H} 1 n=4 ; \mathrm{B} 7 \mathrm{H} 2 n=4)$, and RA SF (ICOS $n=8 ; \mathrm{B} 7 \mathrm{RP} 1 n=7$; B7RP.2 $n=7$; B7H1 $n=7$; B7H2 $n=7$; lower panel) is shown. Populations of naive $\mathrm{CD} 3+/ \mathrm{CD} 4+$ or $\mathrm{CD} 3+/ \mathrm{CD} 8+$ lymphocytes expressing either ICOS or B7 molecules were only slightly above background for all groups in NL PB, RA PB, and RA SF ( $n$, number of different patients).

expressing lymphocytes from NL PB, RA PB, and RA SF. No significant statistical differences were seen with $\mathrm{CD} 45 \mathrm{RO}+/ \mathrm{CD} 3+/ \mathrm{CD} 8+$ and any of the other groups examined. Figure 4 is a representative dot-plot of $\mathrm{CD} 45 \mathrm{RO}+/ \mathrm{CD} 3+/ \mathrm{CD} 4+$ lymphocytes from the various patient SFs. As shown in the dot-plots, large memory $\mathrm{CD} 3+/ \mathrm{CD} 4+$ lymphocyte populations from the RA SF expressed both ICOS and the ICOS ligands B7RP.1 and B7RP.2.

\section{Flow Cytometry Analysis of Memory CD14 Monocytes in NL PB, RA PB, and RA SF}

CD14 monocyte expression of ICOS, B7RP.1, B7RP.2, $\mathrm{B} 7 \mathrm{H} 1$, and $\mathrm{B} 7 \mathrm{H} 2$ was analyzed by FACS analysis and the results are shown in Figures 5 and 6. As shown in Figure 5 , an increased population of CD14 + monocytes expressing ICOS, B7RP.1, B7RP.2, B7H1, and B7H2 is seen in RA SF compared to both NL and RA PB. Figure 6 is a representative dot-plot showing the significantly elevated populations of RA SF CD14+ monocytes expressing B7 mole-
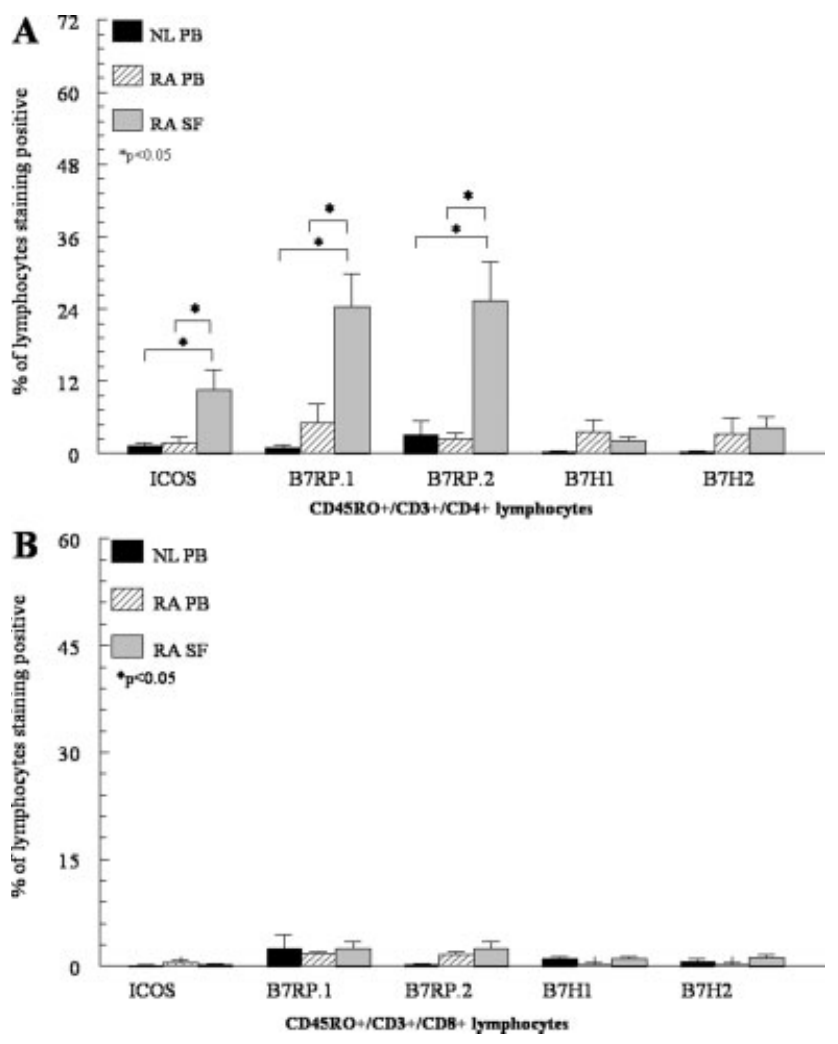

FIG. 3. Comparisons of the number of memory $\mathrm{CD} 45 \mathrm{RO}+/ \mathrm{CD} 3+/$ CD $4+$ lymphocytes from NL PB (ICOS $n=4 ; \operatorname{B7RP} .1 n=4 ; \operatorname{B} 7 \mathrm{RP} .2 n=$ 4; B7H1 $n=4$; B7H2 $n=4$ ), RA PB (ICOS $n=5$; B7RP.1 $n=4$; B7RP.2 $n=4 ; \mathrm{B} 7 \mathrm{H} 1 n=4 ; \mathrm{B} 7 \mathrm{H} 2 n=4)$, and RA SF (ICOS $n=6$; B7RP. $1 n=7$; B7RP.2 $n=7$; B7H1 $n=7$; B7H2 $n=7$; upper panel) and CD45RO+/ CD3+/CD8+ lymphocytes from NL PB (ICOS $n=4 ;$ B7RP. $1 n=4$; B7RP. $2 n=4$; B7H1 $n=4$; B7H2 $n=4)$, RA PB (ICOS $n=5 ; \mathrm{B} 7 \mathrm{RP} .1 n=$ 4 ; B7RP. $n=4$; B7H1 $n=4$; B7H2 $n=4$ ), and RA SF (ICOS $n=8$; B7RP.1 $n=7$; B7RP.2 $n=7$; B7H1 $n=7$; B7H2 $n=7$; lower panel) is shown. Populations of memory CD3+/CD4+, but not CD3+/CD8+ lymphocytes expressing ICOS and the ICOS ligands B7RP.1 and B7RP.2 molecules were elevated in RA SF compared to NL and RA PB $(P<0.05, n$, number of different patients). Thus, RA SF CD3 + lymphocyte populations expressing B7RP.1 and B7RP.2 molecules in Figure 1 were likely memory CD45RO+/CD3+/CD4+ lymphocytes. This indicates that infiltrating memory lymphocytes may be induced to express antigen presenting accessory molecules and that these lymphocyte populations may participate in antigen processing in the RA joint.

cules as well as ICOS. Thus, APCs express B7 molecules and ICOS in RA SF, but PB CD14+ monocytes do not.

\section{Immunohistochemistry of RA ST for ICOS and $\mathrm{B} 7 \mathrm{H} 2$ Expression}

[Figure 7 shows a photomicrograph of RA ST immunostained for ICOS. As indicated (see arrows), lymphocytes are immunoreactive for ICOS. As seen in Figure 8, RA ST dendritic-like cells were also intensely immunoreactive for B7H2. Immunoreactive leukocytes were blindly identified by morphological features by a pathologist (magnification $400 \times$ ). Table 1 outlines cellular expression of $\mathrm{B} 7 \mathrm{H} 1$, B7H2, B7RP.1, and B7RP.2 in RA and NL ST. As indicated, only $\mathrm{B} 7 \mathrm{H} 2$ dendritic-like cell expression was significantly elevated in RA ST compared to NL ST.] 
NL PB

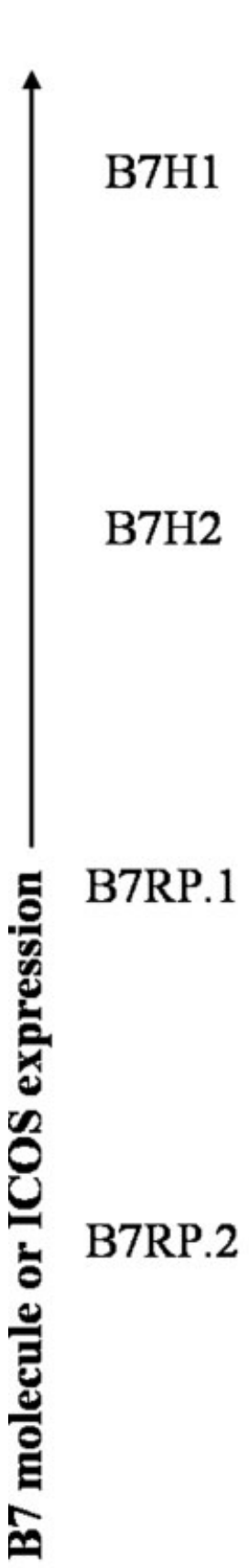

$\operatorname{ICOS}$

G0084573: 26

G0085356: 30
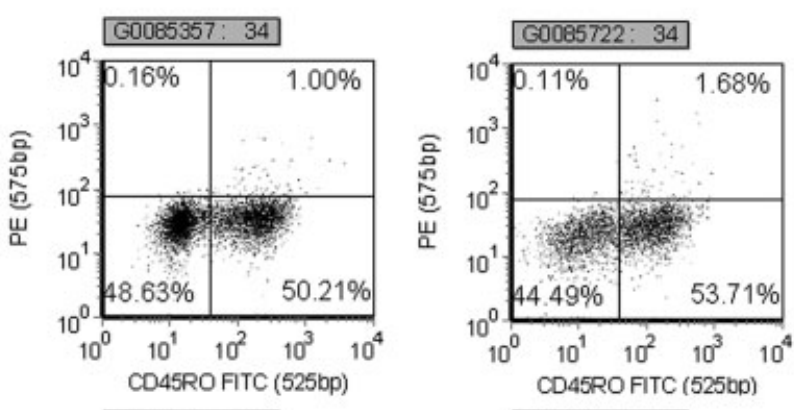

RA PB
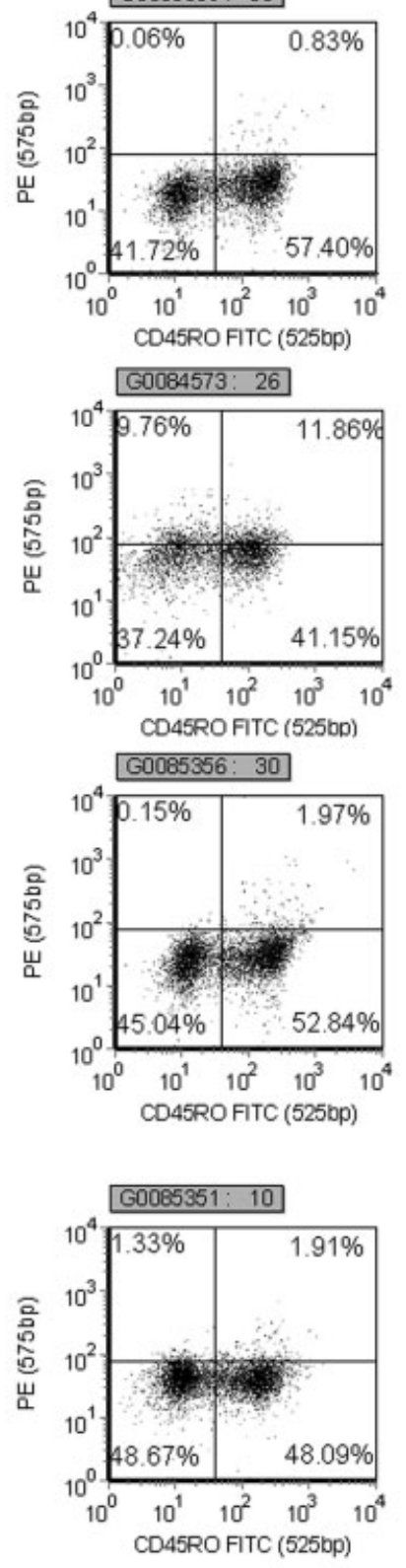

G0085723: 38

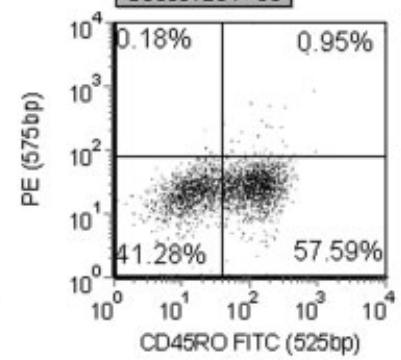

G0085720: 26

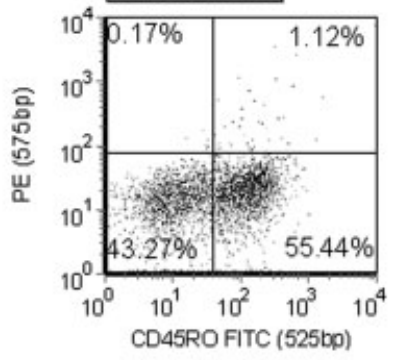

G0085721: 30
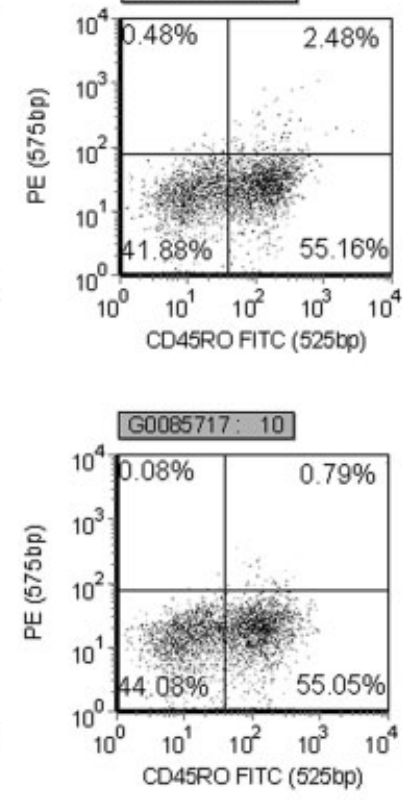

RA SF
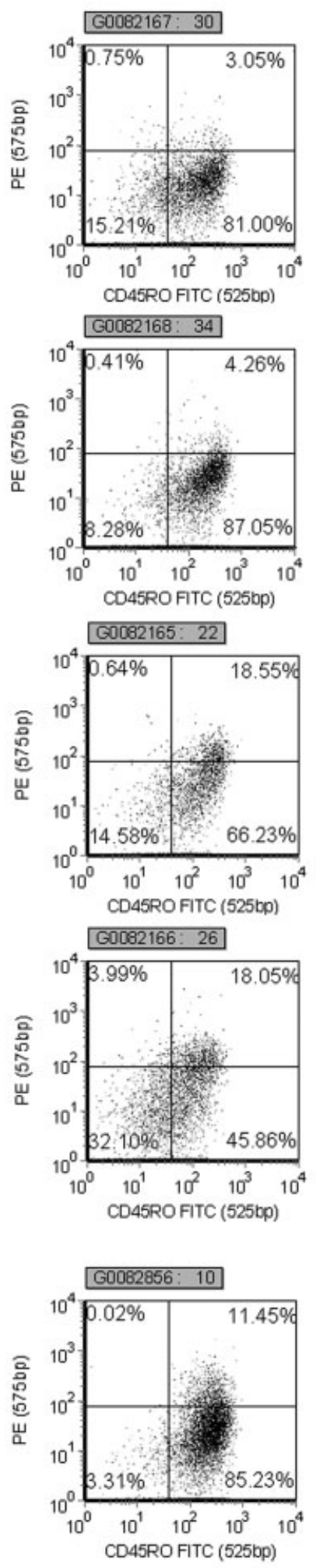

\section{CD45RO+/CD3+/CD4+ expression}

FIG. 4. Representative histograms (dot plots) showing ICOS, B7H1, B7H2, B7RP.1, and B7RP.2 expression on memory CD45RO+/CD3+/CD4+ lymphocytes. As shown, significant populations of memory CD3+/CD4+ lymphocytes expressing ICOS, and the ICOS ligands B7RP.1, and B7RP.2 were found in the RA SF, but not NL or RA PB. NL, normal; PB, peripheral blood; SF, synovial fluid. 


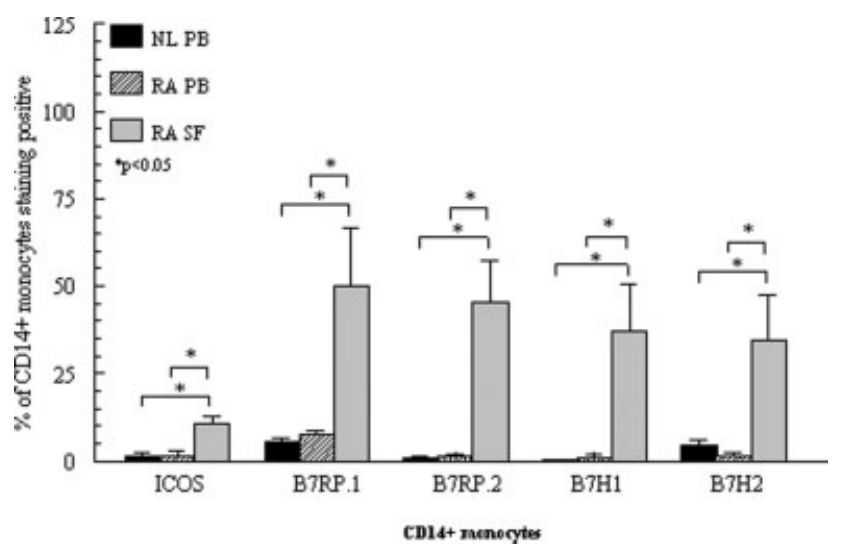

FIG. 5. Expression of ICOS and B7 accessory molecules on CD14+ monocytes from NL PB (ICOS $n=5$; B7RP. $1 n=5$; B7RP. $2 n=5$; B7H1 $n=5$; B7H2 $n=4$ ), RA PB (ICOS $n=4$; B7RP. $1 n=5$; B7RP. $2 n=5$; B7H1 $n=5$; B7H2 $n=5$ ), and RA SF (ICOS $n=4$; B7RP. $n=4 ; \mathrm{B} 7 \mathrm{RP} .2$ $n=4$; $\mathrm{B} 7 \mathrm{H} 1 n=3$; $\mathrm{B} 7 \mathrm{H} 2 n=3$ ). Elevated populations of $\mathrm{CD} 14+$ monocytes expressing ICOS, the ICOS ligands B7RP.1, B7RP.2, and the PD-1 and PD-2 ligands $\mathrm{B} 7 \mathrm{H} 1$ and $\mathrm{B} 7 \mathrm{H} 2$ respectively were found in RA SF compared to NL or RA PB ( $P<0.05, n$, number of different patients). This indicates that monocytes in the RA joint respond to both positive and negative influences as joint inflammation progresses.

\section{DISCUSSION}

RA is an autoimmune disease of unknown etiology associated with increased angiogenic activity (12-14), and cellular recruitment to the joints $(10,11,15,16)$. Inflammatory responses in the RA joint can be attributed in large part to activated T-cells in the RA ST and SF (17). T-cells become further activated via their constituitively expressed CD28 receptors when presented with antigen from an APC, along with appropriate signals from APC accessory molecules like B7.1 and B7.2. These interactions are known to provide potent proinflammatory signals to T-cells, resulting in autocrine IL-2 production, which is important for Tlymphocyte proliferation (1,3,5,18-21). Importance of CD28 costimulation has been directly demonstrated by blocking CD28 and B7 interactions and preventing T-cell responses in autoimmune disease models. In some cases, this has resulted in prolonged tissue acceptance in organ transplant models $(1,22)$.

The newest members of the $\mathrm{B} 7$ family, namely $\mathrm{B} 7 \mathrm{H} 1$, B7H2, B7RP.1, and B7RP.2, have several distinctive features including expression on B lymphocytes (23), and broader expression in nonlymphoid tissues (24). However, B7 molecule family members have also been shown to serve contrasting functions in immunology. For example, $\mathrm{B} 7 \mathrm{H} 1$ and $\mathrm{B} 7 \mathrm{H} 2$, also known as PD-L1 (program death ligand 1) and PD-L2, respectively, are known to be expressed on B cells and dendritic cells. They are also expressed on monocytes that deliver key lymphocytic apoptotic signals by engaging the PD-1 receptor on activated T-lymphocytes, thus attenuating certain immune responses (1). Conversely, ICOS is an activation marker expressed on activated T-cells that binds B7RP.1 expressing monocytes. ICOS engagement with B7RP.1, along with an appropriate antigen, is believed to induce critical activation signals to the T-cell that exacerbate the response (1). This process implicates the antigen, along with an appropriate APC signal, to dictate how activated T-cells will respond. This produces a biased Type 1 (Th1) or Type 2 (Th2) cytokine mediated response that triggers associated chemokine secretion and selective cell recruitment to inflammatory sites (25).

Interestingly, ICOS engagement also augments induction of both Type 1 and Type 2 cytokines, indicating its importance in both polarized Type 1 and Type 2 inflammatory reactions. Correspondingly, Type 1 and Type 2 cytokines can also influence ICOS expression on numerous cell subsets. For example, ICOS expression is upregulated on murine NK cells, where ICOS dependent cytotoxicity and IFN- $\gamma$ production is observed through the phosphoinositide 3-kinase pathway (26). Furthermore, in a murine model of airway hyperactivity, bronchial lymph node cell production of IL-10, a Type 2 associated cytokine, is mediated through the ICOS pathway (27). These studies indicate a strong relationship between ICOS expression and Type 1 and Type 2 immunity. However, the latter finding is further supported by a recent report showing intraperitoneal treatment of mice with anti-ICOS neutralizing antibodies during the sensitization phase with ovalbumin results in decreased airway eosinophilia and IL-5 production (28). Additionally, it has been shown that type 2 lymphocytes secreting IL-10 have elevated ICOS expression (29). Thus, Type 1 and Type 2 lymphocytes express ICOS, but it is generally acknowledged that Type 2 lymphocytes express greater amounts of ICOS than Type 1 cells $(1,6,20,21,30)$. This could explain, in part, the attenuating effects of blocking ICOS during Type 2 inflammatory reactions. These findings strongly support the idea that ICOS blockade is a viable therapeutic strategy for targeting anamnestic, allergic type hypersensitivity reactions.

Because of the noticeably elevated expression of ICOS on Type 2 cells, it has been questioned whether ICOS blockade in Type 1 cytokine mediated reactions may show benefit in tempering Type 1 inflammation. This notion was recently tested in a Type 1 mediated murine EAE model in which ICOS blockade markedly reduced EAE severity (7). Specifically, EAE progression was significantly reduced by administering blocking antibodies to ICOS during the efferent phase of the immune response (days 9-20), a time when the disease course adopts a Type 1 profile. Interestingly, anti-ICOS antibody administration during the priming phase of EAE (days 0-9) exacerbated the disease, likely due to inhibition of an early Type 2 response. Development of this Type 2 reaction may have naturally tempered a later Type 1 response (7). In agreement with these findings is a report by Iwai et al., showing reduction of murine CIA development, a prototypical Type 1 disease, was achieved by administering neutralizing, anti-B7 antibodies capable of blocking B7 and ICOS interactions after the boosting (antigen priming) phase of CIA (8). In agreement, Nurieva et al., showed ICOS knockout CIA susceptible DBA-1 mice are completely resistant to CIA development and joint inflammation (9). Taken together, these results indicate ICOS and B7 
NL PB

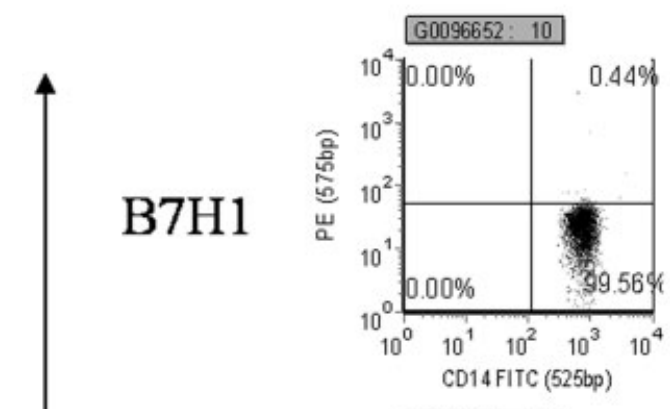

$\mathrm{B} 7 \mathrm{H} 2$
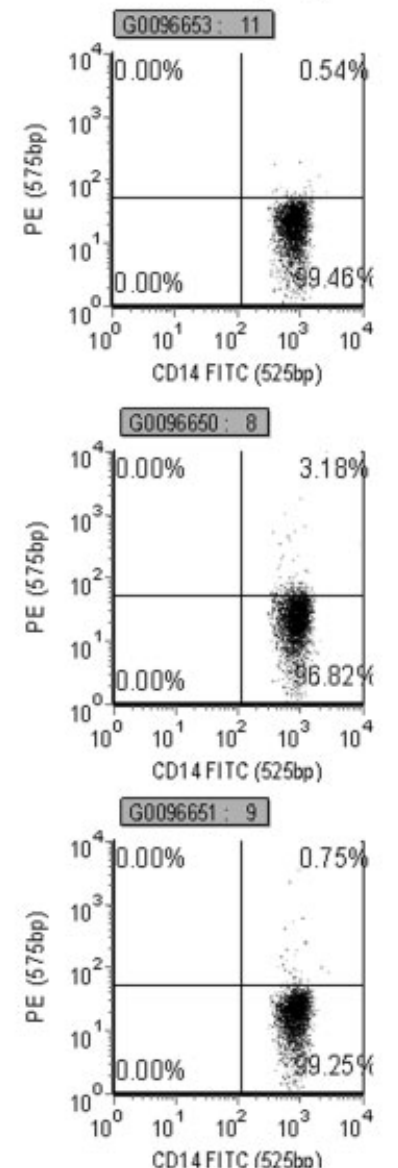

CD14 FITC (525b)

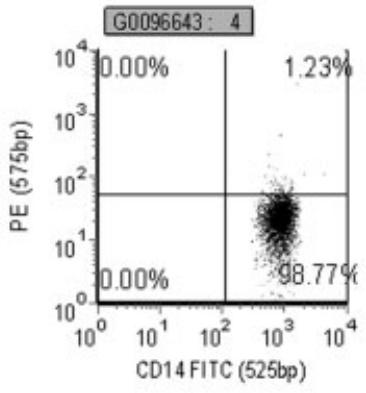

RA PB
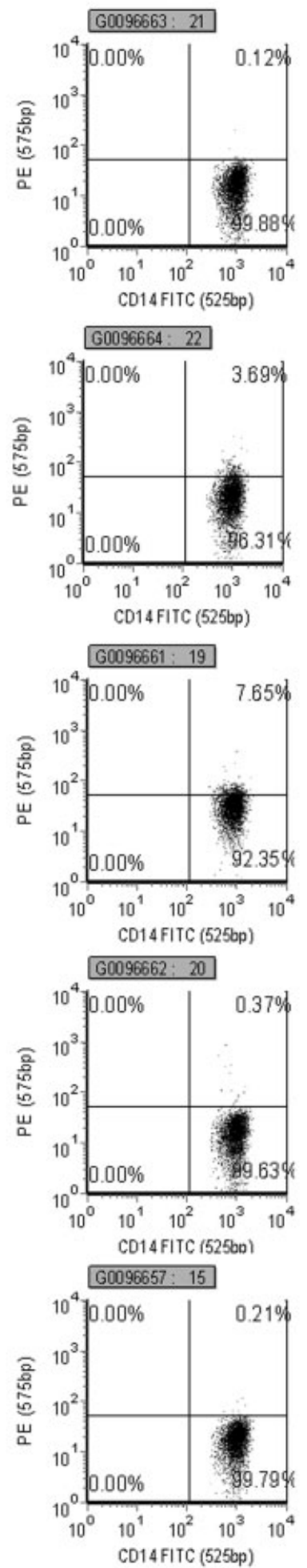

RA SF
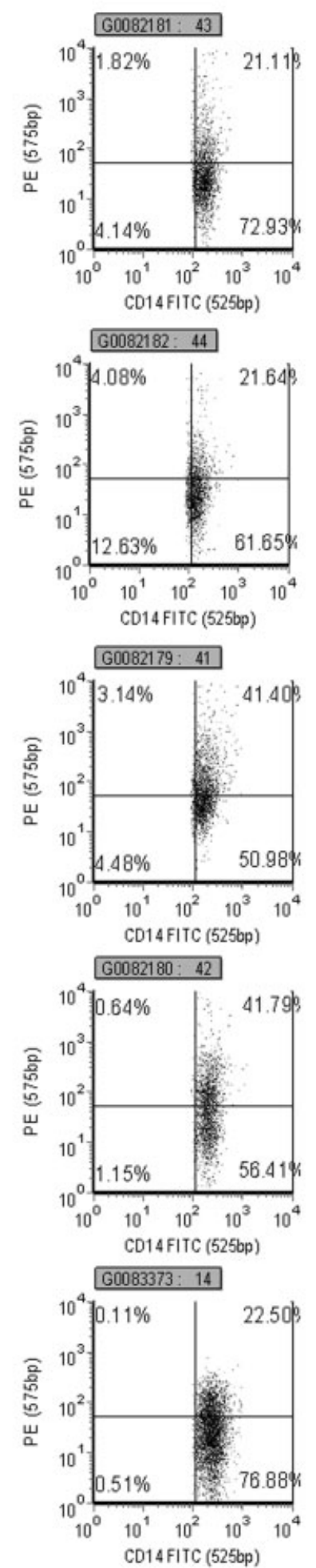

\section{CD14+ expression}

FIG. 6. Representative histograms (dot plots) showing ICOS, B7H1, B7H2, B7RP.1, and B7RP.2 expression on CD14+ monocytes from NL PB, RA PB, and RA SF. As shown, significant populations CD14+ monocytes expressing ICOS, and the ICOS ligands B7RP.1, and B7RP.2, as well as the PD-1 and PD-2 ligands B7H1 and B7H2 respectively were found in RA SF compared to NL and RA PB. NL, normal; PB, peripheral blood; SF, synovial fluid. 

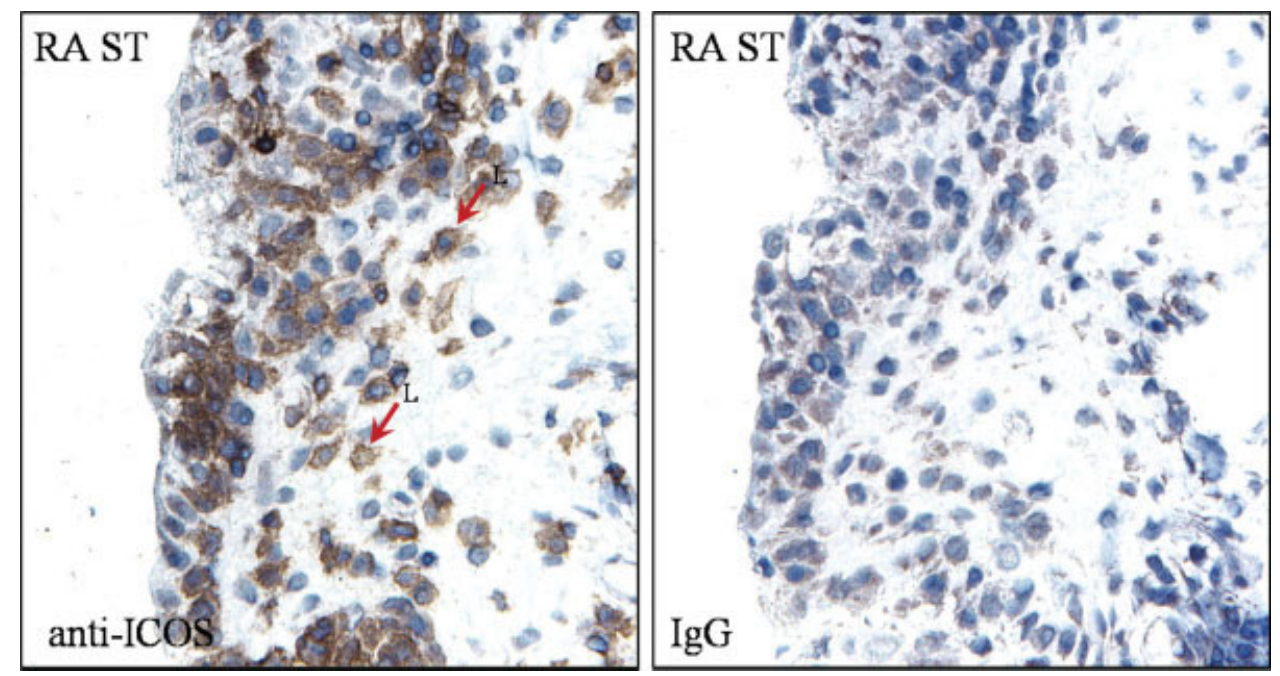

FIG. 7. Photomicrograph of RA ST immunostained for ICOS expression. As shown, scattered lymphocytes in the RA ST stained positive for ICOS (indicated as L, see arrows; original magnification $\times 400$ ). [Color figure can be viewed in the online issue, which is available at www.interscience.wiley.com.]

molecules may play an integral part in the pathogenesis of CIA and other Type 1 diseases. These findings also indicate that antagonizing B7-ICOS interactions may be worthwhile in treating RA, assuming these molecules are significantly expressed in human RA tissues.

The recent study by Okamota et al. describes ICOS expression on CD4+ RA SF cells, and shows by reverse transcriptase polymerase chain reaction (RT-PCR) that RA ST contained elevated mRNA levels of the ICOS ligand B7RP.1 (31). The data herein further defines upregulated populations of ICOS expressing cell subsets, including CD14+ monocytes in RA SF. Furthermore, we clearly demonstrate upregulation of $\mathrm{B} 7$ molecules on RA SF $\mathrm{CD} 14+$ monocytes, indicating activation of the innate immune response in RA patients. We also identified $\sim 25 \%$ of RA SF memory CD3+/CD4+ lymphocytes expressing B7RP-1 or B7RP-2, and $\sim 10 \%$ of memory CD3+/CD $4+$ lymphocytes expressing ICOS. Thus, lymphocytes, as well as monocytes can express ICOS and B7 molecules in RA SF compared to NL or RA PB. This is consistent with our previous study showing T-cells express $\mathrm{B} 7$ molecules in the RA ST (17). It is tempting to speculate that lymphocytes and monocytes may swap ICOS and $\mathrm{B} 7$ molecules during antigen presentation in the RA joint, where there is abundant antigen. This exchange would explain the elevated expression of $\mathrm{B} 7$ that allows synovial $\mathrm{T}$ cells to serve as functional APCs in the rheumatoid joint (17). By this method, functional immune cells could increase or decrease reactivity in the RA joint via the ICOS and/or CD28 pathways.

With respect to ICOS expression on cell subsets during inflammatory responses, the question arises whether ICOS expressing leukocyte populations are specifically recruited to the RA joint, or stimulated to express ICOS upon entering the joint? The latter explanation is unlikely considering that in vivo interperitoneal blockade of ICOS
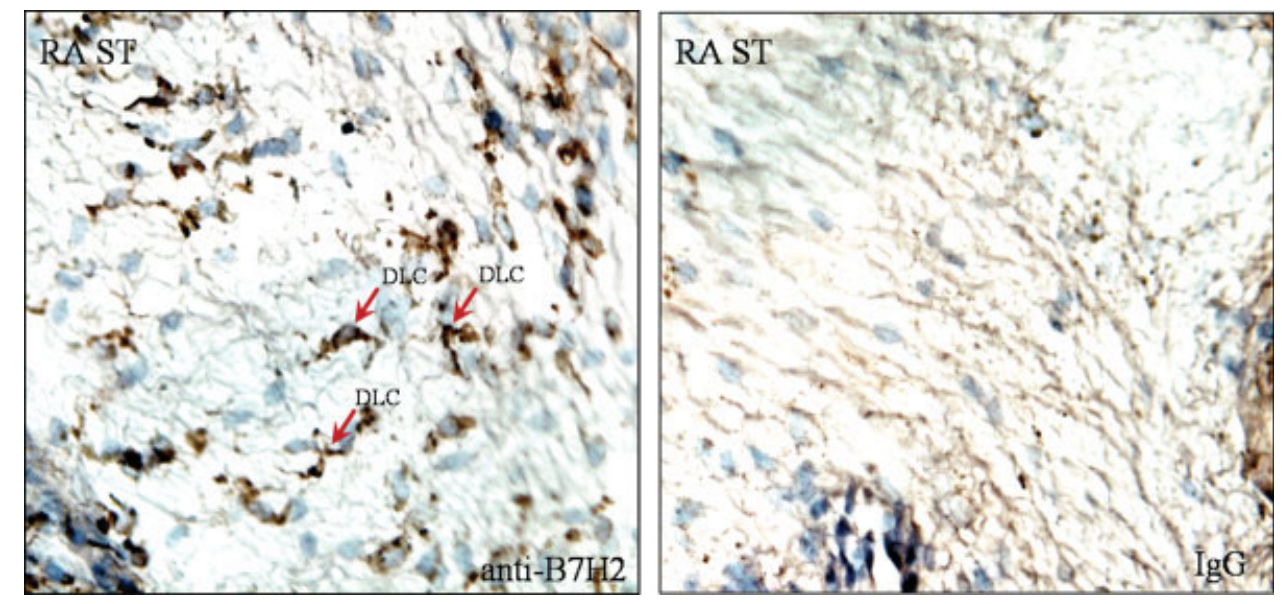

FIG. 8. Photomicrograph of RA ST immunostained for B7H2. As shown, intense B7H2 staining of ST APCs (dendritic-like cells) was found in RA compared to NL ST (indicated as DLC, see arrows; original magnification $\times 400$ ). [Color figure can be viewed in the online issue, which is available at www. interscience.wiley.com.] 
Table 1

B7 Molecule Staining in RA and NL Synovial Tissues

\begin{tabular}{|c|c|c|c|c|c|c|c|c|c|}
\hline & Inflm score & $\operatorname{Vasc}(1-4)$ & Line \% & Macs \% & $\mathrm{EC} \%$ & SM \% & Lymph \% & DC \% & $\mathrm{Fib} \%$ \\
\hline \multicolumn{10}{|l|}{ NL ST } \\
\hline \multicolumn{10}{|l|}{ B7RP.1 } \\
\hline Mean & 1 & 2 & 38 & 1 & 0 & 0 & 0 & 11 & 0 \\
\hline$S E M \pm$ & 0.0 & 0.0 & 21.2 & 0.8 & 0.0 & 0.0 & 0.0 & 6.7 & 0.0 \\
\hline No. of tissues & 6 & 6 & 6 & 6 & 6 & 6 & 6 & 6 & 6 \\
\hline \multicolumn{10}{|l|}{ B7RP.2 } \\
\hline Mean & 1 & 2 & 7 & 2 & 0 & 0 & 0 & 18 & 0 \\
\hline$S E M \pm$ & 0.0 & 0.2 & 4.7 & 0.9 & 0.0 & 0.0 & 0.0 & 5.0 & 0.2 \\
\hline No. of tissues & 6 & 6 & 6 & 6 & 6 & 6 & 6 & 6 & 6 \\
\hline \multicolumn{10}{|l|}{ B7H1 } \\
\hline Mean & 1 & 2 & 0 & 0 & 0 & 0 & 0 & 12 & 0 \\
\hline$S E M \pm$ & 0.2 & 0.2 & 0.0 & 0.2 & 0.0 & 0.0 & 0.0 & 7.2 & 0.0 \\
\hline No. of tissues & 6 & 6 & 6 & 6 & 6 & 6 & 6 & 6 & 6 \\
\hline \multicolumn{10}{|l|}{ B7H2 } \\
\hline Mean & 1 & 2 & 0 & 3 & 0 & 0 & 0 & 13 & 0 \\
\hline$S E M \pm$ & 0.2 & 0.3 & 0.0 & 3.3 & 0.0 & 0.0 & 0.0 & 4.8 & 0.0 \\
\hline No. of tissues & 6 & 6 & 6 & 6 & 6 & 6 & 6 & 6 & 6 \\
\hline \multicolumn{10}{|l|}{ RA ST } \\
\hline \multicolumn{10}{|l|}{ B7RP.1 } \\
\hline Mean & 2 & 2 & 36 & 6 & 0 & 0 & 0 & 16 & 1 \\
\hline$S E M \pm$ & 0.3 & 0.3 & 20.3 & 3.0 & 0.2 & 0.3 & 0.0 & 7.0 & 0.9 \\
\hline No. of tissues & 6 & 6 & 6 & 6 & 6 & 6 & 6 & 6 & 6 \\
\hline \multicolumn{10}{|l|}{ B7RP.2 } \\
\hline Mean & 2 & 2 & 21 & 1 & 0 & 0 & 0 & 15 & 0 \\
\hline$S E M \pm$ & 0.2 & 0.0 & 17.4 & 1.0 & 0.0 & 0.0 & 0.0 & 5.3 & 0.0 \\
\hline No. of tissues & 6 & 6 & 6 & 6 & 6 & 6 & 6 & 6 & 6 \\
\hline \multicolumn{10}{|l|}{ B7H1 } \\
\hline Mean & 3 & 3 & 15 & 5 & 0 & 0 & 0 & 6 & 0 \\
\hline$S E M \pm$ & 0.3 & 0.3 & 12.2 & 4.1 & 0.0 & 0.0 & 0.0 & 1.4 & 0.0 \\
\hline No. of tissues & 6 & 6 & 6 & 6 & 6 & 6 & 6 & 6 & 6 \\
\hline \multicolumn{10}{|l|}{ B7H2 } \\
\hline Mean & 3 & 3 & 37 & 20 & 0 & 0 & 0 & $46^{*}$ & 1 \\
\hline$S E M \pm$ & 0.2 & 0.2 & 20.7 & 14.1 & 0.0 & 0.0 & 0.0 & 14.2 & 1.0 \\
\hline No. of tissues & 6 & 6 & 6 & 6 & 6 & 6 & 6 & 6 & 6 \\
\hline
\end{tabular}

${ }^{*} P<0.05$ NL ST compared to RA ST.

Inflm score, inflammatory score; Vasc, vascular score; Line, lining cells; Macs, macrophages; EC, endothelial cells; SM, smooth muscle cells; Lymp, lymphocytes; DC, dendritic-like cells; Fib, fibroblasts.

before development of inflammation shows marked effects on EAE development (7). However, it is currently unknown whether these lymphocyte populations are specifically recruited to the RA joint by coexpression of chemokine receptors. We are currently examining these possibilities with in vitro multicolor flow cytometry experiments. [Nevertheless, leukocytes do over express ICOS and $\mathrm{B} 7 \mathrm{H} 2$ in $\mathrm{RA}$ ST, as immunohistochemical analysis showed robust staining for lymphocyte ICOS and APC (dendritic like cell) $\mathrm{B} 7 \mathrm{H} 2$ expression.] Interestingly, we identified B7 molecules on RA SF CD14+ monocytes known to down-regulate T-cell activation through PD-1 (B7H1 and 2), and upregulate T-cell activation through B7RP.1. [We also show in Table 1 that RA ST associated dendritic-like cells significantly express $\mathrm{B} 7 \mathrm{H} 2$ compared to NL ST.] Thus, in the same joint, there appear to be both positive and negative influences, in which positive, proinflammatory forces may be dominating as the RA patient becomes symptomatic. It is also possible that negative feedback signals begin to dominate as joint inflammation resolves, for example, due to RA therapy. Thus, leukocytes bearing ICOS and $\mathrm{B} 7$ molecules may be critical mediators of joint inflammation, partly responsible for the waxing and waning nature associated with RA.

Overall, these findings suggest that $\mathrm{CD} 3+/ \mathrm{CD} 4+$ memory lymphocytes, because of upregulated costimulatory and ICOS molecule expression, are primed for lymphocyte recruitment and activation in RA. This data identifies increased populations of cell subsets expressing B7 molecules and ICOS in RA, and strongly indicates that ICOS and/or B7 molecule blockade may be a relevant target for RA treatment.

\section{ACKNOWLEDGMENTS}

The authors would like to thank Mary Paniagua and Jeffery Nelson of the Lurie Cancer Center of Northwestern University for assisting with the flow cytometry studies. Their expert technical assistance helped to make these studies possible. Thanks also go to Dr. David Fox of the University of Michigan Rheumatology Division for his advice and helpful comments. We would also like to thank Drs. Christy Park, Elizabeth Chang, and Rui Cerejo of Northwestern University Rheumatology Division for providing patient RA PB and SF samples. 


\section{LITERATURE CITED}

1. Carreno BM, Collins M. The B7 family of ligands and its receptors: New pathways for costimulation and inhibition of immune responses. Annu Rev Immunol 2002;20:29-53.

2. Beier KC, Hutloff A, Dittrich AM, Heuck C, Rauch A, Buchner K, Ludewig B, Ochs HD, Mages HW, Kroczek RA. Induction, binding specificity and function of human ICOS. Eur J Immunol 2000;30: 3707-3717.

3. Hutloff A, Dittrich AM, Beier KC, Eljaschewitsch B, Kraft R, Anagnostopoulos I, Kroczek RA. ICOS is an inducible T-cell co-stimulator structurally and functionally related to CD28. Nature 1999;397:263266.

4. Mages HW, Hutloff A, Heuck C, Buchner K, Himmelbauer H, Oliveri F, Kroczek RA. Molecular cloning and characterization of murine ICOS and identification of $\mathrm{B} 7 \mathrm{~h}$ as ICOS ligand. Eur J Immunol 2000;30: 1040-1047.

5. Yoshinaga SK, Whoriskey JS, Khare SD, Sarmiento U, Guo J, Horan T, Shih G, Zhang M, Coccia MA, Kohno T, Tafuri-Bladt A, Brankow D, Campbell P, Chang D, Chiu L, Dai T, Duncan G, Elliott GS, Hui A, McCabe SM, Scully S, Shahinian A, Shaklee CL, Van G, Mak TW, Senaldi G. T-cell co-stimulation through B7RP-1 and ICOS. Nature 1999; 402:827-832.

6. McAdam AJ, Chang TT, Lumelsky AE, Greenfield EA, Boussiotis VA, Duke-Cohan JS, Chernova T, Malenkovich N, Jabs C, Kuchroo VK, Ling V, Collins M, Sharpe AH, Freeman GJ. Mouse inducible costimulatory molecule (ICOS) expression is enhanced by CD28 costimulation and regulates differentiation of CD4 + T cells. J Immunol 2000;165: 5035-5040.

7. Rottman JB, Smith T, Tonra JR, Ganley K, Bloom T, Silva R, Pierce B, Gutierrez-Ramos JC, Ozkaynak E, Coyle AJ. The costimulatory molecule ICOS plays an important role in the immunopathogenesis of EAE. Nat Immunol 2001;2:605-611.

8. Iwai H, Kozono Y, Hirose S, Akiba H, Yagita H, Okumura K, Kohsaka H, Miyasaka N, Azuma M. Amelioration of collagen-induced arthritis by blockade of inducible costimulator-B7 homologous protein costimulation. J Immunol 2002;169:4332-4339.

9. Nurieva RI, Treuting P, Duong J, Flavell RA, Dong C. Inducible costimulator is essential for collagen-induced arthritis. J Clin Invest 2003;111:701-706

10. Ruth JH, Rottman JB, Katschke KJ Jr, Qin S, Wu L, LaRosa G, Ponath P, Pope RM, Koch AE. Selective lymphocyte chemokine receptor expression in the rheumatoid joint. Arthritis Rheum 2001;44:27502760.

11. Ruth JH, Volin MV, Haines GK III, Woodruff DC, Katschke KJ Jr, Woods JM, Park CC, Morel JC, Koch AE. Fractalkine, a novel chemokine in rheumatoid arthritis and in rat adjuvant-induced arthritis. Arthritis Rheum 2001;44:1568-1581.

12. Szekanecz Z, Koch AE. Chemokines and angiogenesis. Curr Opin Rheumatol 2001;13:202-208.

13. Szekanecz Z, Szegedi G, Koch AE. Angiogenesis in rheumatoid arthritis: Pathogenic and clinical significance. J Investig Med 1998;46:27-41.

14. Koch AE, Harlow LA, Haines GK, Amento EP, Unemori EN, Wong WL, Pope RM, Ferrara N. Vascular endothelial growth factor. A cytokine modulating endothelial function in rheumatoid arthritis. J Immunol 1994;152:4149-4156.

15. Ruth JH, Shahrara S, Park CC, Morel JC, Kumar P, Qin S, Koch AE. Role of macrophage inflammatory protein-3 $\alpha$ and its ligand CCR6 in rheumatoid arthritis. Lab Invest 2003;83:579-588.

16. Katschke KJ Jr, Rottman JB, Ruth JH, Qin S, Wu L, LaRosa G, Ponath P, Park CC, Pope RM, Koch AE. Differential expression of chemokine receptors on peripheral blood, synovial fluid, and synovial tissue monocytes/macrophages in rheumatoid arthritis. Arthritis Rheum 2001; 44:1022-1032.

17. Verwilghen J, Lovis R, De Boer M, Linsley PS, Haines GK, Koch AE, Pope RM. Expression of functional B7 and CTLA4 on rheumatoid synovial T cells. J Immunol 1994;153:1378-1385.

18. Wang S, Zhu G, Chapoval AI, Dong $\mathrm{H}$, Tamada $\mathrm{K}$, Ni J, Chen L. Costimulation of $\mathrm{T}$ cells by $\mathrm{B} 7-\mathrm{H} 2$, a B7-like molecule that binds ICOS. Blood 2000;96:2808-2813.

19. Yoshinaga SK, Zhang M, Pistillo J, Horan T, Khare SD, Miner K, Sonnenberg $M$, Boone $T$, Brankow D, Dai T, Delaney J, Han $\mathrm{H}$ Hui A, Kohno T, Manuoukian R, Whoriskey JS, Coccia MA. Characterization of a new human B7-related protein: B7RP-1 is the ligand to the co-stimulatory protein ICOS. Int Immunol 2000;12:14391447.

20. Gonzalo JA, Tian J, Delaney T, Corcoran J, Rottman JB, Lora J, Algarawi A, Kroczek R, Gutierrez-Ramos JC, Coyle AJ. ICOS is critical for $\mathrm{T}$ helper cell-mediated lung mucosal inflammatory responses. Nat Immunol 2001;2:597-604.

21. Riley JL, Blair PJ, Musser JT, Abe R, Tezuka K, Tsuji T, June CH. ICOS costimulation requires IL- 2 and can be prevented by CTLA- 4 engagement. J Immunol 2001;166:4943-4948.

22. Salomon B, Bluestone JA. Complexities of CD28/B7: CTLA-4 costimulatory pathways in autoimmunity and transplantation. Annu Rev Immunol 2001;19:225-252.

23. Liang L, Porter EM, Sha WC. Constitutive expression of the B7h ligand for inducible costimulator on naive $B$ cells is extinguished after activation by distinct $\mathrm{B}$ cell receptor and interleukin 4 receptor-mediated pathways and can be rescued by CD40 signaling. J Exp Med 2002; 196:97-108.

24. Liang L, Sha WC. The right place at the right time: Novel B7 family members regulate effector $\mathrm{T}$ cell responses. Curr Opin Immunol 2002;14:384-390.

25. Chensue SW, Warmington K, Ruth J, Lincoln P, Kuo MC, Kunkel SL. Cytokine responses during mycobacterial and schistosomal antigeninduced pulmonary granuloma formation. Production of Th1 and Th2 cytokines and relative contribution of tumor necrosis factor. Am J Pathol 1994;145:1105-1113.

26. Ogasawara K, Yoshinaga SK, Lanier LL. Inducible costimulator costimulates cytotoxic activity and IFN- $\gamma$ production in activated murine NK cells. J Immunol 2002;169:3676-3685.

27. Akbari O, Freeman GJ, Meyer EH, Greenfield EA, Chang TT, Sharpe AH, Berry G, DeKruyff RH, Umetsu DT. Antigen-specific regulatory T cells develop via the ICOS-ICOS-ligand pathway and inhibit allergeninduced airway hyperreactivity. Nat Med 2002;8:1024-1032.

28. Wiley RE, Goncharova S, Shea T, Johnson JR, Coyle AJ, Jordana M. Evaluation of inducible costimulator/B7-related protein-1 as a therapeutic target in a murine model of allergic airway inflammation. Am J Respir Cell Mol Biol 2003;28:722-730.

29. Witsch EJ, Peiser M, Hutloff A, Buchner K, Dorner BG, Jonuleit H, Mages HW, Kroczek RA. ICOS and CD28 reversely regulate IL-10 on reactivation of human effector $\mathrm{T}$ cells with mature dendritic cells. Eur J Immunol 2002;32:2680-2686.

30. Coyle AJ, Lehar S, Lloyd C, Tian J, Delaney T, Manning S, Nguyen T, Burwell T, Schneider H, Gonzalo JA, Gosselin M, Owen LR, Rudd CE, Guttierrez-Ramos JC. The CD28-related molecule ICOS is required for effective T cell-dependent immune responses. Immunity 2000;13:95105.

31. Okamoto T, Saito S, Yamanaka H, Tomatsu T, Kamatani N, Ogiuchi H, Uchiyama T, Yagi J. Expression and function of the co-stimulator H4/ ICOS on activated $\mathrm{T}$ cells of patients with rheumatoid arthritis. J Rheumatol 2003;30:1157-1163. 